\title{
ORIGINAL ARTICLE \\ Electrocardiographic abnormalities in the early stage following traumatic spinal cord injury
}

\author{
JC Furlan ${ }^{1,2,3}$, F Verocai ${ }^{4,5}$, X Palmares ${ }^{6}$ and MG Fehlings ${ }^{7,8,9}$
}

\begin{abstract}
Study design: Retrospective cohort study.
Objective: Although cardiac arrhythmias are relatively well recognized in the chronic stage after spinal cord injury (SCl), little is known regarding its occurrence during the early stage. The objective of this study was to examine electrocardiogram changes within the first $72 \mathrm{~h}$ after acute traumatic SCl.
\end{abstract}

Setting: Acute spine trauma center, Toronto, Ontario, Canada

Methods: This study included all consecutive patients with spine trauma admitted to our institution from January 1998 to June 2007 who had an electrocardiogram within the first $72 \mathrm{~h}$ post trauma. Patients were divided into four groups: (I) patients with motor complete $\mathrm{SCl}$ at T6 or above; (II) patients with motor incomplete SCI at T6 or above; (III) patients with spine trauma but no/minor SCl at T6 or above; and (IV) patients with SCl below T6.

Results: There were 69 men and 20 women with mean age of 53.8 years (16-88 years). All groups were comparable regarding age, sex, pre-existing comorbidities and cause of SCl. There were no significant differences among the groups regarding predominant rhythm, PR interval, atrial-ventricular conduction, ventricular rate, QRS axis and intraventricular conduction abnormalities. Nonetheless, patients in Group I had longer RR interval $(P=0.016)$, longer QTc $(P=0.025)$ and more prolonged duration of the longest QRS $(P=0.017)$ in comparison with the other groups.

Conclusions: Our results indicate that electrocardiogram abnormalities are more common within the first $72 \mathrm{~h}$ following acute traumatic, motor complete, cervical or high-thoracic SCl. This may represent early manifestations of autonomic dysfunction due to disruption of descending cardiovascular pathways in individuals with severe $\mathrm{SCl}$ at $\mathrm{T} 6$ or above.

Spinal Cord (2016) 54, 872-877; doi:10.1038/sc.2016.11; published online 16 February 2016

\section{INTRODUCTION}

Traumatic spinal cord injury (SCI) has a global incidence that varies from 8 to 246 cases per million inhabitants per year and a global prevalence estimated at 236-1298 per million inhabitants. ${ }^{1}$ Despite its relatively low incidence, traumatic SCI can result in devastating motor, sensory and autonomic impairment, resulting in lifelong disability and limited participation in social activities or the workforce.

In a prior systematic review comparing the most cited articles with consumers' perspectives, the major focus of the literature was on motor assessment and recovery, whereas autonomic dysfunction was cited as the second most disruptive consequence for individuals with $\mathrm{SCI}^{2}$ Although neurogenic bowel, neurogenic bladder and sexual dysfunction are commonly recognized autonomic dysfunctions among spinal cord-injured individuals, cardiovascular disorders due to loss of supraspinal control of the sympathetic nervous system are also common and limiting. ${ }^{3,4}$ Baseline low systemic blood pressure, orthostatic hypotension and episodes of sudden increase in blood pressure (that is, autonomic dysreflexia) are the predominant cardiovascular disorders of arterial blood pressure control after SCI at T6 or above. ${ }^{4}$ In addition to hemodynamic abnormalities, SCI can lead to cardiac arrhythmia including sinus bradycardia, supraventricular arrhythmia, ventricular arrhythmia and cardiac arrest. ${ }^{5-8}$ Although these cardiac arrhythmias are relatively well recognized in the subacute and chronic stages after SCI, there is a paucity of studies focused on abnormal cardiac electrical activity during the early stages following SCI.

Early manifestations of cardiovascular complications after traumatic SCI have been associated with the disruption of the descending vasomotor (cardiovascular) in patients with motor complete, cervical or high-thoracic SCI. ${ }^{4,9}$ Although alterations in the blood pressure control and heart rate (in particular, bradycardia) have been reported in the early stage after traumatic SCI, little is known on the abnormalities of the heart rhythm and other cardiac arrhythmias in the early phase of SCI. Given that loss of supraspinal sympathetic control on cardioregulation supposedly occurs during the primary injury of the spinal cord after trauma, we hypothesized that patients

${ }^{1}$ Department of Medicine, Division of Neurology, University of Toronto, Toronto, Ontario, Canada; ${ }^{2}$ Department of Medicine, Division of Physical Medicine and Rehabilitation, University of Toronto, Toronto, Ontario, Canada; ${ }^{3}$ Lyndhurst Centre, Toronto Rehabilitation Institute, University Health Network, Toronto, Ontario, Canada; ${ }^{4}$ Department of Cardiology, Hospital Samaritano, Rio de Janeiro, Brazil; ${ }^{5}$ Department of Cardiology, Hospital Universitário Clementino Fraga Filho, Rio de Janeiro, Brazil; ${ }^{6}$ Department of Cardiovascular Surgery, Hospital Municipal de Teixeira de Freitas, Teixeira de Freitas, Brazil; ${ }^{7}$ Department of Surgery, Division of Neurosurgery, University of Toronto, Toronto, Ontario, Canada; ${ }^{8}$ Department of Surgery, Division of Neurosurgery, University Health Network, Toronto, Ontario, Canada and ${ }^{9}$ Krembil Neuroscience Centre, Spinal Program, Toronto Western Hospital, University Health Network, Toronto, Ontario, Canada

Correspondence: Dr JC Furlan, Lyndhurst Centre, Toronto Rehabilitation Institute, University Health Network, 520 Sutherland Drive, Room 205, Toronto, Ontario, Canada M4G 3V9.

E-mail: jcfurlan@gmail.com

Received 10 August 2015; revised 13 December 2015; accepted 15 December 2015; published online 16 February 2016 
with more severe, cervical or high-thoracic (at T6 or above) are at a greater risk of developing abnormal heart rate and/or rhythm within the first $72 \mathrm{~h}$ after acute traumatic SCI. With this, we carried out the present study to examine the electrocardiographic changes within the first $72 \mathrm{~h}$ after acute spine trauma and their potential association with the level and severity of SCI.

\section{SUBJECTS AND METHODS}

The University Health Network Research Ethics Board (UHN-REB) approved the study protocol. This retrospective cohort study included all consecutive cases of spine trauma admitted to the Toronto Western Hospital, an acute spine trauma center in Ontario (Canada), from January 1998 to June 2007 that had at least one electrocardiogram within the first $72 \mathrm{~h}$ post trauma. We excluded individuals with a history of prior cardiac arrhythmia, patients knowingly taking any drug that could cause QT prolongation or affect the cardiac conduction system and pregnant patients. Electrocardiograms were read and interpreted by two cardiologists (XP and FV) who were blinded to the patients' clinical information. Definitions of the ECG parameters included in this study are stated elsewhere. ${ }^{10}$

Baseline data included age at the time of SCI, sex, Charlson comorbidity index, cause of SCI, severity and level of SCI. Pre-existing medical conditions were classified using the Charlson Comorbidity Index, which was originally derived from data from medical patients for prediction of mortality using 19 diseases weighted on the basis of their association with in-hospital and 1-year mortality. ${ }^{11}$ According to the Charlson Comorbidity Index, selected preexisting medical conditions were assigned respective weights for estimation of the index as follows: weight of 1-myocardial infarction, congestive heart disease, peripheral vascular disease, cerebrovascular disease, dementia, chronic pulmonary disease, connective tissue disease, ulcer disease, mild liver disease and diabetes; weight of 2-hemiplegia, moderate or severe renal disease, diabetes with end organ damage, any tumor, leukemia and lymphoma; weight of 3-moderate or severe liver disease; weight of 6-metastatic solid tumor and acquired immune deficiency syndrome. ${ }^{11}$

Table 1 Comparisons of baseline data among the groups of (I) patients with motor complete spinal cord injury $(\mathrm{SCl})$ at T6 or more cranial level, (II) patients with motor incomplete $\mathrm{SCI}$ at $\mathrm{T} 6$ or more cranial level, (III) patients with spine trauma at $\mathrm{T} 6$ or more cranial level but no/minor $\mathrm{SCl}$, and (IV) patients with $\mathrm{SCl}$ caudal to the T6 level

\begin{tabular}{|c|c|c|c|c|c|}
\hline Characteristics & $\begin{array}{l}\text { Group I } \\
(n=29)\end{array}$ & $\begin{array}{l}\text { Group II } \\
(n=16)\end{array}$ & $\begin{array}{l}\text { Group III } \\
(\mathrm{n}=35)\end{array}$ & $\begin{array}{c}\text { Group IV } \\
(\mathrm{n}=9)\end{array}$ & P-values \\
\hline \multicolumn{6}{|l|}{ Age (years) } \\
\hline Mean \pm s.e.m. & $52 \pm 4$ & $61 \pm 4$ & $55 \pm 3$ & $42 \pm 5$ & 0.095 \\
\hline Median & 50 & 62.5 & 55 & 42 & \\
\hline \multicolumn{6}{|l|}{$\operatorname{Sex}(n)$} \\
\hline Males & 24 & 13 & 25 & 7 & 0.722 \\
\hline Females & 5 & 3 & 10 & 2 & \\
\hline \multicolumn{6}{|c|}{ Charlson comorbidity index (n) } \\
\hline 0 & 25 & 11 & 29 & 8 & 0.181 \\
\hline 1 & 3 & 5 & 3 & 0 & \\
\hline$\geqslant 2$ & 1 & 0 & 3 & 1 & \\
\hline \multicolumn{6}{|l|}{ Cause of $\mathrm{SCl}$} \\
\hline Fall & 19 & 10 & 22 & 6 & 0.304 \\
\hline $\begin{array}{l}\text { Motor vehicle } \\
\text { accident }\end{array}$ & 4 & 6 & 9 & 1 & \\
\hline Other causes ${ }^{a}$ & 6 & 0 & 4 & 2 & \\
\hline
\end{tabular}

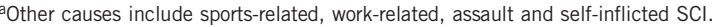

All cases were classified according to the severity of SCI as assessed by the ASIA Impairment Scale (AIS) into the following: (i) patients with motor and sensory complete SCI (AIS A) or motor complete but sensory incomplete SCI (AIS B); and (ii) patients with motor incomplete SCI where the majority of the key muscles below the neurological level have a muscle grade less than 3 (AIS C) or the majority of the key muscles below the neurological level have a muscle grade greater than or equal to 3 (AIS D). ${ }^{12}$ The study population was divided into four groups according to the level and severity of SCI as follows: (i) patients with motor complete SCI at T6 or more cranial level; (ii) patients with motor incomplete SCI at T6 or more cranial level; (iii) patients with spine trauma at $\mathrm{T} 6$ or more cranial level but no/minor SCI; and (iv) patients with SCI caudal to the T6 level.

Group comparisons were conducted using analysis of variance with the Bonferroni's post hoc test for continuous variables and the $\chi^{2}$-test for categorical variables. Significance was assumed at $5 \%(P<0.05)$. All data were analyzed using SAS for Windows version 9.2 (SAS Institute Inc., Cary, NC, USA).

\section{RESULTS}

There were 69 men and 20 women with mean age of 53.8 years and a range from 16 to 88 years. The groups were comparable regarding age, sex, pre-existing medical comorbidities and cause of SCI (Table 1).

Moreover, there were no statistically significant differences among the four groups of patients with regard to the following: atrioventricular conduction, intraventricular conduction and predominant rhythm (Table 2); PR interval $(P=0.403)$, ventricular rate $(P=0.122)$ and $\mathrm{QRS}$ axis $(P=0.695$; Figure 1$)$; ST elevation

Table 2 Comparisons of electrocardiogram (ECG) parameters among the groups of (I) patients with motor complete spinal cord injury ( $\mathrm{SCI}$ ) at T6 or more cranial level, (II) patients with motor incomplete $\mathrm{SCl}$ at T6 or more cranial level, (III) patients with spine trauma at T6 or more cranial level but no/minor SCl, and (IV) patients with $\mathrm{SCl}$ caudal to the $\mathrm{T} 6$ level

\begin{tabular}{|c|c|c|c|c|c|}
\hline ECG parameters & $\begin{array}{l}\text { Group I } \\
(\mathrm{n}=29)\end{array}$ & $\begin{array}{l}\text { Group /I } \\
(\mathrm{n}=16)\end{array}$ & $\begin{array}{l}\text { Group III } \\
(\mathrm{n}=35)\end{array}$ & $\begin{array}{c}\text { Group IV } \\
(\mathrm{n}=9)\end{array}$ & P-values \\
\hline \multicolumn{6}{|c|}{ Atrioventricular conduction (n) } \\
\hline Normal & 21 & 14 & 29 & 9 & 0.529 \\
\hline $\begin{array}{l}\text { First-degree AV } \\
\text { block }\end{array}$ & 6 & 1 & 6 & 0 & \\
\hline $\begin{array}{l}\text { Third-degree AV } \\
\text { block }\end{array}$ & 1 & 0 & 0 & 0 & \\
\hline Undetermined & 1 & 1 & 0 & 0 & \\
\hline \multicolumn{6}{|c|}{ Abnormal intraventricular conduction (n) } \\
\hline None & 24 & 12 & 30 & 9 & 0.935 \\
\hline Complete block & 3 & 2 & 2 & 0 & \\
\hline $\begin{array}{l}\text { Left anterior } \\
\text { hemiblock }\end{array}$ & 1 & 1 & 1 & 0 & \\
\hline $\begin{array}{l}\text { Left posterior } \\
\text { hemiblock }\end{array}$ & 1 & 0 & 1 & 0 & \\
\hline $\begin{array}{l}\text { Non-specific } \\
\text { defects }\end{array}$ & 0 & 1 & 1 & 0 & \\
\hline \multicolumn{6}{|c|}{ Predominant rhythm ( $n$ ) } \\
\hline Normal sinus & 17 & 14 & 22 & 6 & 0.33 \\
\hline $\begin{array}{l}\text { Sinus } \\
\text { bradycardia }\end{array}$ & 4 & 0 & 5 & 1 & \\
\hline SVT & 2 & 2 & 4 & 2 & \\
\hline Other rhythms & 6 & 0 & 4 & 0 & \\
\hline
\end{tabular}

Abbreviations: AV, atrioventricular; SVT, supraventricular tachycardia. 

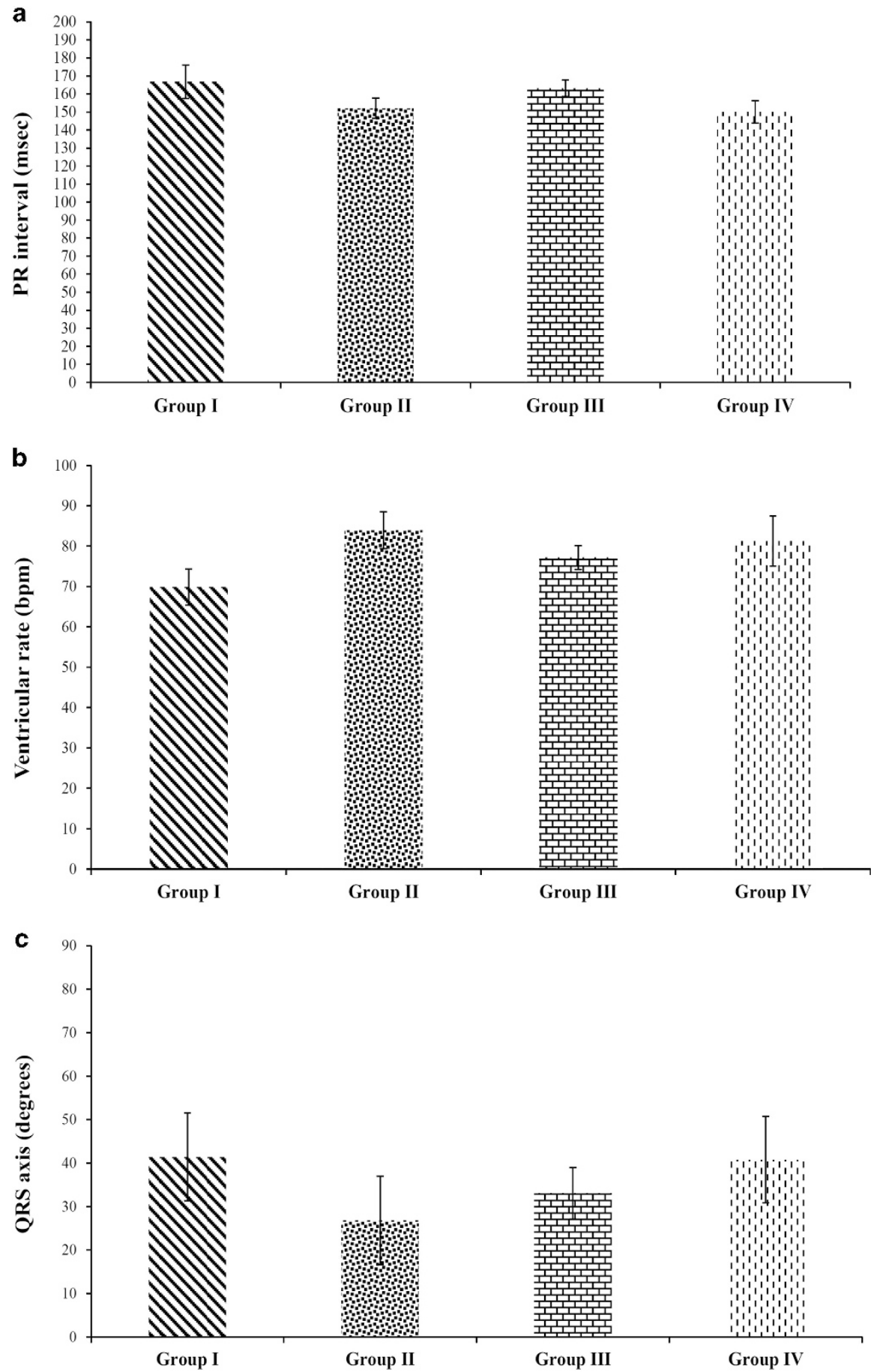

Figure 1 Comparisons of PR interval, ventricular rate and QRS axis among the groups of (I) patients with motor complete spinal cord injury (SCI) at T6 or more cranial level, (II) patients with motor incomplete SCI at T6 or more cranial level, (III) patients with spine trauma at T6 or more cranial level but no/ minor SCl, and (IV) patients with SCl caudal to the T6 level.

$(P=0.385)$, ST depression $(P=0.574)$, early repolarization $(P=0.804)$ and $\mathrm{T}$ inversion $(P=0.238$; Figure 2$)$.

Nonetheless, motor complete SCI at T6 or above was significantly associated with longer RR interval $(P=0.016)$, shorter QTc interval $(P=0.025)$ and more prolonged duration of the longest QRS complex $(P=0.017)$ in comparison with less severe spine trauma caudal to the T6 level (Figure 3).

\section{DISCUSSION}

The results of this study indicate that patients with motor complete SCI at T6 or above developed a more prolonged RR interval, shorter QTc interval and longer duration of the widest QRS complex when compared with patients with less severe SCI caudal to the T6 level within the first $72 \mathrm{~h}$ following spine trauma. However, the level and severity of spine trauma did not adversely affect the frequency of other 
a

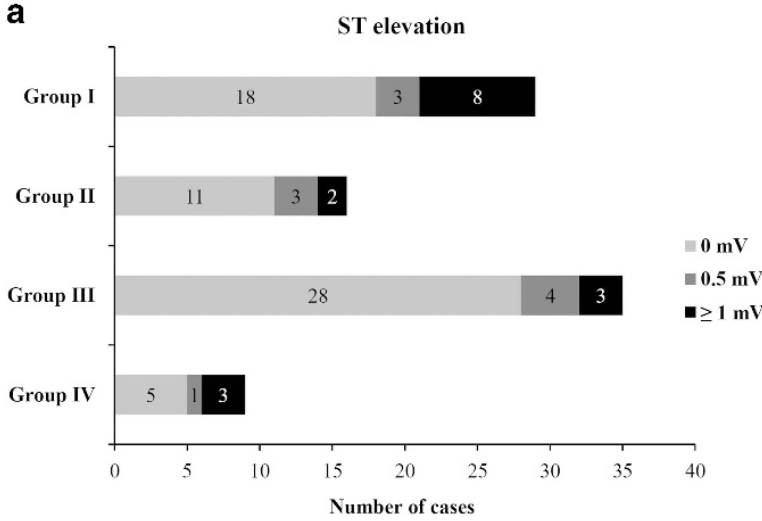

C

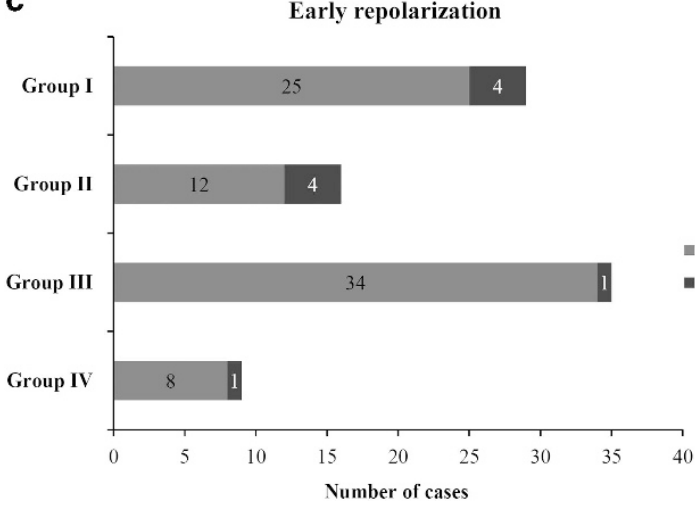

b

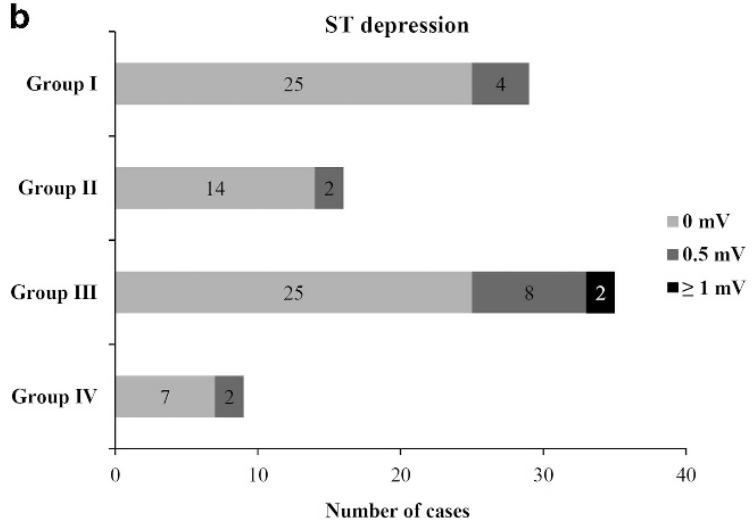

d

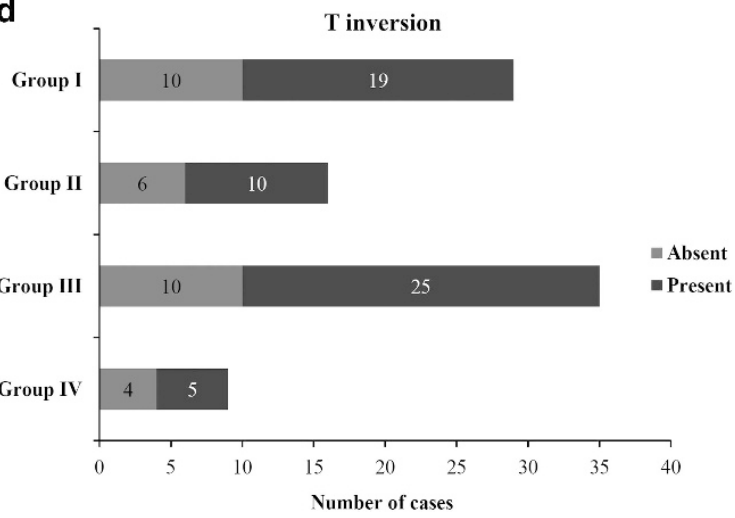

Figure 2 Comparisons of ST elevation (a), ST depression (b), early repolarization (c), and T inversion (d) among the groups of (I) patients with motor complete spinal cord injury (SCI) at T6 or more cranial level, (II) patients with motor incomplete SCl at T6 or more cranial level, (III) patients with spine trauma at $\mathrm{T} 6$ or more cranial level but no/minor SCI, and (IV) patients with $\mathrm{SCl}$ caudal to the T6 level.

electrocardiographic abnormalities that were occasionally seen in patients with acute spine trauma.

Generally speaking, loss of supraspinal sympathetic control results in substantial cardiovascular abnormalities that are more common and critical in patients with motor complete, cervical or high-thoracic SCI. ${ }^{9}$ In addition to the level and severity of spine trauma, the timing from the trauma considerably influences the frequency and severity of cardiovascular complications following SCI. ${ }^{4,9}$ During the acute stage after SCI, the autonomic nervous system is in a state of instability (so-called 'spinal shock') that is commonly accompanied by significant cardiac arrhythmias and blood pressure abnormalities. ${ }^{13}$ Failure of cardioregulatory mechanisms and hemodynamic control can occur at any stage; however, the chronic stage is usually characterized by lessening of autonomic instability over time. ${ }^{13}$

There is a growing body of evidence in the literature indicating different neurophysiological changes attributed to cardioregulatory dysfunction during the acute stage after traumatic cervical or highthoracic SCI. For instance, bradycardia was described in $64-77 \%$ of patients during the acute stage after cervical SCI. ${ }^{8,14,15}$ Bunten et al. ${ }^{13}$ reported that tetraplegics are more susceptible to low frequency and impaired variability of heart rate when compared with paraplegics and able-bodied individuals. Using both 24-h Holter monitoring and 12lead ECG, Bartholdy et al. ${ }^{5}$ documented that patients with cervical SCI had significantly lower heart rates within the first month post injury when compared with patients with thoracic SCI. Their results also suggested that patients with cervical SCI are more susceptible to bradycardia, sinus node arrest, supraventricular tachycardia and, more rarely, cardiac arrest during the first month after cervical SCI, whereas only a few patients with thoracic SCI developed sinus node arrests and bradycardia. ${ }^{5}$

The present study is an original examination of several electrocardiographic parameters during the initial $72 \mathrm{~h}$ post trauma among patients grouped according to their level and severity of spine trauma. Overall, this study shows that patients with motor complete SCI at cervical or high-thoracic level had significantly longer RR interval, shorter QTc interval and more prolonged duration of the longest QRS complex than patients with less severe spine trauma caudal to the T6 level. These findings may be explained by the fact that patients with severe cervical SCI have marked imbalance between the sympathetic and the parasympathetic nervous systems. The results of the present also suggest that the level and severity of spine trauma do not significantly affect several other electrocardiographic parameters including predominant rhythm, PR interval, atrioventricular conduction, ventricular rate, QRS axis, intraventricular conduction abnormalities, ST elevation, ST depression, T inversion and early depolarization. Similar results were reported in prior investigations that included only individuals with chronic SCI. For instance, Leaf et $a .^{7}$ found that patients with cervical SCI had similar frequencies of cardiac arrhythmias when compared with patients with thoracic SCI during the chronic stage after trauma. Prakash et al. ${ }^{16}$ also documented no significant differences between a group of individuals with chronic SCI and a group of able-bodied individuals with regard to the frequency of right bundle branch block, left bundle branch block, left ventricular hypertrophy with strain, premature ventricular contraction, any Q wave abnormality, abnormal QTc, left atrial abnormality, intraventricular conduction delay, atrial fibrillation, 


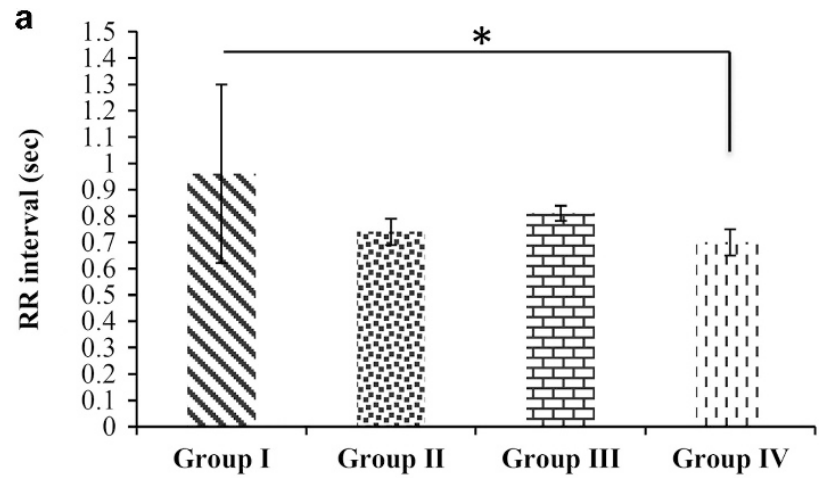

study has indicated several practical challenges (e.g., obtaining informed consent, sedation, surgery, other investigations, and transfer to other hospitals) that precluded obtaining a prolonged Holter recording in this group of patients. ${ }^{5}$ Finally, all patients included in this study were admitted to a spine trauma center, which can also be a source of selection bias, even though it has the advantage of more specialized surgical and medical spine care.

\section{CONCLUSIONS}

The results of this study revealed relevant electrocardiogram abnormalities with the initial $72 \mathrm{~h}$ after acute spine trauma that presumably are associated with impairment of sympathetic control of the heart. In addition, the level and severity of SCI were only associated with the following cardiac neurophysiological abnormalities: the RR interval, QTc interval and duration of the slowest QRS complex. Although other electrocardiogram changes were also identified in the early stage following spine trauma, the level and severity of the injury did not significantly affect predominant rhythm, PR interval, atrioventricular conduction, ventricular rate, QRS axis, intraventricular conduction abnormalities, ST elevation, ST depression, $\mathrm{T}$ inversion and early depolarization. Future investigations using larger and prospectively accrued data are needed to determine whether electrocardiogram abnormalities in the early stage after trauma are of predictive value for cardiovascular complications and survival following acute spine trauma.

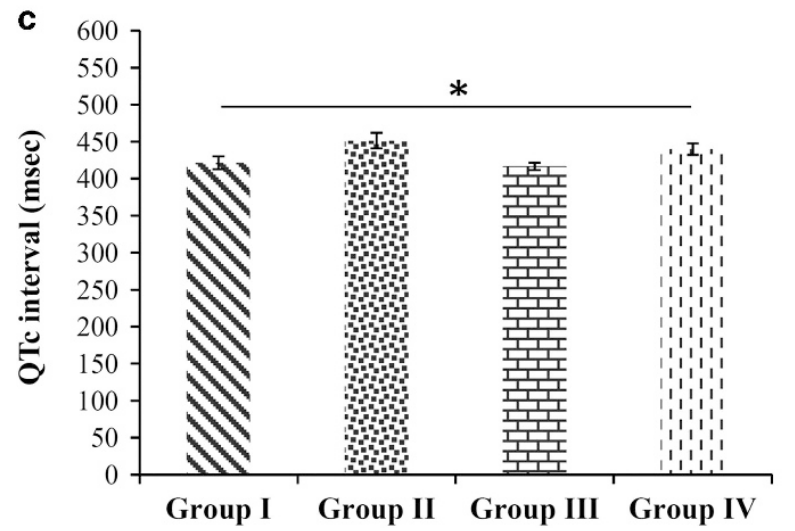

\section{DATA ARCHIVING}

There were no data to deposit.

\section{CONFLICT OF INTEREST}

The authors declare no conflict of interest.

\section{ACKNOWLEDGEMENTS}

JCF is supported by the Toronto Rehab Foundation. MGF is supported by the Halbert Chair in Neural Repair and Regeneration and by the Dezwirek Foundation.

Figure 3 Comparisons of RR interval, QRS duration and QTc interval among the groups of (I) patients with motor complete spinal cord injury (SCI) at T6 or more cranial level, (II) patients with motor incomplete SCI at T6 or more cranial level, (III) patients with spine trauma at T6 or more cranial level but no/minor SCl, and (IV) patients with $\mathrm{SCl}$ caudal to the T6 level. Asterisks identifies significant differences as per Bonferroni's post hoc test

ST elevation and ST depression. More recently, Akbal et al. ${ }^{17}$ reported that individuals developed greater QT dispersion (but similar P-wave dispersion) during the chronic stage following SCI when compared with control subjects.

\section{Study limitations}

Although this study reports important electrocardiographic findings that occurred during early stage after SCI, there are limitations that should be taken into consideration when interpreting and applying those results. First, this retrospective cohort study included only patients who had at least one electrocardiogram within the first $72 \mathrm{~h}$ post injury, and, hence, selection bias is a possibility. Second, 12-lead electrocardiogram captures only a short recording of cardiac electrical activity, whereas prolonged Holter monitoring would be more sensitive for capturing electrical abnormalities. Nonetheless, a prior

1 Furlan JC, Sakakibara BM, Miller WC, Krassioukov AV. Global incidence and prevalence of traumatic spinal cord injury. Can J Neurol Sci 2013; 40: 456-464.

2 Furlan JC, Fehlings MG. A Web-based systematic review on traumatic spinal cord injury comparing the "citation classics" with the consumers' perspectives. J Neurotrauma 2006; 23: 156-169.

3 Furlan JC. Autonomic dysreflexia: a clinical emergency. J Trauma Acute Care Surg 2013; 75: 496-500.

4 Furlan JC, Fehlings MG. Cardiovascular complications after acute spinal cord injury: pathophysiology, diagnosis, and management. Neurosurg Focus 2008; 25: E13.

5 Bartholdy K, Biering-Sorensen T, Malmqvist L, Ballegaard M, Krassioukov A, Hansen B et al. Cardiac arrhythmias the first month after acute traumatic spinal cord injury. J Spinal Cord Med 2014; 37: 162-170.

6 Collins HL, Rodenbaugh DW, DiCarlo SE. Spinal cord injury alters cardiac electrophysiology and increases the susceptibility to ventricular arrhythmias. Prog Brain Res 2006: 152: 275-288.

7 Leaf DA, Bahl RA, Adkins RH. Risk of cardiac dysrhythmias in chronic spinal cord injury patients. Paraplegia 1993; 31: 571-575.

8 Lehmann KG, Lane JG, Piepmeier JM, Batsford WP. Cardiovascular abnormalities accompanying acute spinal cord injury in humans: incidence, time course and severity. J Am Coll Cardiol 1987; 10: 46-52.

9 Furlan JC, Fehlings MG, Shannon P, Norenberg MD, Krassioukov AV. Descending vasomotor pathways in humans: correlation between axonal preservation and cardiovascular dysfunction after spinal cord injury. J Neurotrauma 2003; 20: 1351-1363.

10 Goldschlager N, Goldman MJ. Electrocardiography: Essentials of Interpretation. Lange Medical Publications: Los Altos, CA, USA, 1984.

11 Charlson ME, Pompei P, Ales KL, MacKenzie CR. A new method of classifying prognostic comorbidity in longitudinal studies: development and validation. J Chronic Dis 1987; 40: 373-383. 
12 Furlan JC, Fehlings MG, Tator CH, Davis AM. Motor and sensory assessment of patients in clinical trials for pharmacological therapy of acute spinal cord injury: psychometric properties of the ASIA Standards. J Neurotrauma 2008; 25: 1273-1301.

13 Bunten DC, Warner AL, Brunnemann SR, Segal JL. Heart rate variability is altered following spinal cord injury. Clin Auton Res 1998; 8: 329-334.

14 Piepmeier JM, Lehmann KB, Lane JG. Cardiovascular instability following acute cervical spinal cord trauma. Cent Nerv Syst Trauma 1985; 2: 153-160.
15 Winslow EB, Lesch M, Talano JV, Meyer PR Jr. Spinal cord injuries associated with cardiopulmonary complications. Spine 1986; 11: 809-812.

16 Prakash M, Raxwal V, Froelicher VF, Kalisetti D, Vieira A, O'Mara G et al. Electrocardiographic findings in patients with chronic spinal cord injury. Am J Phys Med Rehabil 2002; 81: 601-608.

17 Akbal A, Kurtaran A, Gurcan A, Selcuk B, Batgi H, Akyuz M et al. P-wave and QT dispersion in spinal cord injury. Intern Med 2014; 53: 1607-1611. 